\title{
Emerging issues in energy, climate change and sustainability management
}

\author{
Margot HURLBERT, Mac OSAZUWA-PETERS \\ University of Regina, Regina, Canada
}

\begin{abstract}
:
Aim: This editorial article provides a general introduction into the topic of this special issue on emerging issues in energy, climate change and sustainability management.
\end{abstract}

Design/Research methods: This article is based on a comprehensive review of this special edition journal and a comparison of the findings in the individual articles.

Findings: Barriers to sustainability include cost, regulatory architecture and perceptions of sustainability. Synergies of growing biomass, expanding biomass with carbon capture and sequestration to mitigate climate change have tradeoffs with food security.

Originality/value of the article: The main value of this introductory article of the special issue is that it provides an overview of the articles identifying barriers of regulatory architecture and perceptions to sustainability and synergies and tradeoffs highlighted in the articles.

Keywords: sustainability management, climate change synergies and tradeoffs, carbon capture and sequestration.

JEL: O13, Q01, Q4, Q5, Q54

The concept of sustainability is driving actions in both corporate and public spheres and at multiple layers of society. For example, current practices in resource exploration, usage and consumption are largely believed to be unsustainable, resulting in problems such as climate change and calls for action in mitigating climate change. However, climate change is a wicked problem, where actions to

Correspondence address: Mac Osazuwa-Peters, Margot Hurlbert, 309.1 Johnson Shoyama School Of Public Policy, 3rd Floor, College Avenue Campus, 2155 College Avenue, University Of Regina, E-mail: Mac.Osazuwa-Peters@Uregina.ca (Mac Osazuwa-Peters), margot.hurlbert@uregina.ca (Margot Hurlbert).

Received: 06.03.2020, Accepted: 09.03.2020

doi: http://dx.doi.org/10.29015/cerem.873 


\section{Margot HURLBERT, Mac OSAZUWA-PETERS}

change current unsustainable practices causing climate change, result in new, sometimes unintended, challenges. Climate change is also a multi sector problem and this special issue focuses on challenges emerging as jurisdictions attempt to move toward sustainability in the energy sector. These challenges are known to have the capacity to either slow down the drive forward sustainable practices or completely inhibit a move toward a more sustainable energy future.

The scope of this special issue offers readers a look at some emerging issues in the broad subject area of sustainable energy and climate change management from a research, policy and practical viewpoint. The papers in the special issue discuss emerging challenges to a sustainable energy future using specific case studies; they highlight the different contexts influencing these challenges and responses or actions to meet them. This special issue covers the world - including Nigeria, Mauritius, the Seychelles, Canada (the city of Saskatoon in Saskatchewan and provinces of Alberta and Saskatchewan), Sweden, and the United States (the city of Anchorage in Alaska, and States of North Dakota and Texas). The papers of this special issue consider challenges of sustainability while also discussing solutions in relation to technology, policy, and governance.

The articles discuss clean energy technologies and resources including wind, solar, hydro, geothermal energy, carbon capture and storage (CCS), and biomass. This special issue notes several obstacles to deploying these technologies, including regulatory architecture (Analyzing the Regulatory framework for Carbon Capture and Storage), and perceptions of climate change (Governance and decentralized energy transitions). Each article discussed below outlines recommendations for policies and strategies for overcoming these obstacles. For example, regional solutions for cooperation and governance are outlined by "Islands in the Energy Stream".

To be sustainable, climate change strategies must minimize trade-offs and build on synergies. In "The Impact of climate change on the value of growing maize as a biofuel" the trade-offs of growing biomass and the impacts of climate change are illustrated. Further consideration includes impacts on food security. Future sustainability will require that multiple complex problems like these are considered. 
At a time when climate change is a crisis, utilization of all tools will be required. Current fossil fuel infrastructure will require CCS in the future to meet the 2050 goals of net zero carbon. "Analyzing Regulatory Framework for CCS" makes an important contribution for reducing risk of stranded infrastructure and bridging the technological transition to net zero emissions. While policies are important, regulations set the foundation for governance of sustainability management practices. Actors that include governments, cities, multilateral organizations, and regional associations and their important role are highlighted in these articles. A summary of the articles follows.

Sally Olasogba and Les Duckers provide another African case study in "The Impact of climate change on the value of growing maize as a biofuel. As awareness about the dangers of a carbon intense global system dependent on burning fossil fuels increase, calls to replace fossil fuel energy sources with renewable ones are growing. Thus, renewable resources such as wind, hydro, geothermal, wave and tidal energies are being deployed or explored. However, since every country in the world has some capacity for biomass, this article examines the role that a changing climate could have on the growing and processing of biomass for power generation purposes. The article points out a major concern for the use of biomass being climate change itself which could adversely affect the yield of crops, such as maize which are used in biomass processes. The study used four different Nigerian agricultural zones (AEZ) growing maize and modelled future climate conditions in each while forecasting the impact that such conditions may have on the yield of maize, and by extension the potential of biomass use in Nigeria. As climate change increases, biomass yields may decrease, an important factor in considerations of power production sources in the future.

Small island developing states are the focus in "Islands in the Energy Stream: Regional cooperation to enhance carbon literacy via integrated renewable energy initiatives." In this article, Roy Smith and Rachel Welton considers the critical need for multi-stakeholder cooperation in creating a "coherent and sustainable response" to emergencies that may result in the future due to climate change. They argue that self-contained small island developing states (SIDS) provide an interesting case for "examining the roles and agendas of the varying stakeholders that need to cooperate 
in order to address and sustainably manage the challenges and opportunities involved in developing and implementing integrated renewable energy policies and practices". The article goes ahead to discuss some of the challenges in hammering out a framework for cooperation among stakeholders, but shows the role of multilateral organizations such as the Indian Ocean Commission (IOC) and the Indian Ocean Rim Association (IORA) in creating appropriate frameworks for collaborative engagement and cooperation to take place. While broadly discussing SIDS, the article focuses on Mauritius and the Seychelles.

While the advent of an electric grid in a rural community in Guatemala provided increased opportunity for earned income it also increased vulnerability due to frequent and prolonged power failures. Thus in "Evaluating the Use of Renewable Energy and Communal Governance Systems for Climate Change Adaptation." Deborah Ley et al. highlight the need for enhanced and continuous monitoring and evaluation methods for both energy projects and their supporting institutional structures. These processes help to increase reliability. Strong bonds of trust are necessary for community resilience in emergencies and for well-being and development of community independent of energy sources. Set in the aftermath of Hurricane Stan, the study shows that accountability, mediation mechanisms and transparency tools within energy institutions can allow more open communication and equitable treatment with agents of power. While findings don't invalidate the case for polycentric governance, they point to these circumstances that need to be met for community management of common-pool resources to be effective and sustainable.

This next paper by Martin Boucher examines the influence of different governance frameworks on decentralized energy transitions efforts in three jurisdictions: Luleå (Sweden), Saskatoon (Canada), and Anchorage (United States). Based on community case studies conclusions surrounding good governance are made in "Governance and decentralized energy transitions: a comparative case study of three medium sized cities in Sweden, Canada, and the United State." Through a comparative analysis of these regions, the study presents five governance dimensions that impact decentralized energy transitions. Further, it explains shows that these factors provide a more contextual understanding of patterns of 
decentralized energy transitions in cities. Innovative decentralized energy (DE) projects are growing around the world - from solar co-ops with unique ownership structures and energy efficient and self-generating systems for low income residences. There are also integrated combined heat and power (CHP) systems that provide community district heating to ambitious wind projects in some of the harshest weather conditions. These DE cases highlight the role of cities in climate change mitigation efforts. However, having more cities engage in DE projects require a clear understanding of governance frameworks that enable it, or otherwise slow it down. Five governance dimensions were found to be important for advancing DE in cities: utility market structure, multi-sector collaboration, decisionmaking capacity and autonomy, multilevel governance, and public perceptions of climate change. However, the conclusion of the research was the contextual interactions between these governance dimensions, and not one single dimension that was notable. This gave rise to new research questions including whether regulated or deregulated policy communities are more facilitative of DE?, How much does city level autonomy and capacity impact DE transitions?

Many scenarios to maintain global warming below 2 degrees Celsius require combinations of new technology including carbon capture and storage (CCS). As China and India increase the number of coal power plants being built, CCS increasingly plays a role in meeting global carbon commitments made in the Paris Agreement. However, a gap in implementation exists. The article "Analyzing Regulatory Framework for Carbon Capture and Storage (CCS) Technology Development: A Case Study Approach" by Mac Osazuwa-Peters and Margot Hurlbert considers the role of regulation and policy in closing a gap needed in relation to bridging current infrastructure into a decarbonized future. The focus on CCS cost as a barrier to deployment overshadows the needs for regulatory support as a means of reducing uncertainties and de-risking CCS investments. This article maps the regulatory landscape in six jurisdictions with CCS projects, are currently developing a CCS project or have considered deploying CCS technology. The authors argue that since regulations are grand statements providing contexts for action, they define when and how to act. It is therefore important that a clear analysis of what regulatory architecture currently exist in support of CCS 


\section{Margot HURLBERT, Mac OSAZUWA-PETERS}

technology and to establish what the gaps are. This allows jurisdictions considering CCS technology to make efforts to close the gaps and avoid regulatory pitfalls that have slowed down CCS deployment over the last two decades.

In closing, while each of these articles pertains to specific research, geographies, and contexts they are united in their concern for climate change and sustainability. Lessons within each important for policy makers and actors at all levels can be found. A complex, wicked problem of climate change will require multi sectoral, jurisdictional, and scalar solutions. This special issue advances this conversation. We also added a reflection paper entitled "COVID-19 - reflections on the surprise of both an expected and unexpected event". The current events show that threats for sustainability may appear more quickly that we tend to think. 